\title{
Female Germ Line Mosaicism as the Origin of a Unique IL-2 Receptor $\gamma$-Chain Mutation Causing X-linked Severe Combined Immunodeficiency
}

\author{
Jennifer M. Puck, * Amy E. Pepper, ${ }^{*}$ Pierre-Michel Bédard, ${ }^{\star}$ and Rachel Laframboise ${ }^{\varsigma}$ \\ *Immunologic Genetics Section, Laboratory for Human Gene Transfer, National Center for Human Genome Research, National \\ Institutes of Health, Bethesda, Maryland 20892; ${ }^{\ddagger}$ Department of Immunology and ${ }^{\S}$ Departments of Genetics and Pediatrics, \\ Centre Hospitalier de l'Université Laval, St. Foy, Quebec G1V 4G2, Canada
}

\begin{abstract}
The $I L 2 R G$ gene encoding the $\gamma$ chain of the lymphocyte receptor for IL-2 lies in human Xq13.1 and is mutated in males with $X$-linked severe combined immunodeficiency (SCID). In a large Canadian pedigree genetic linkage studies demonstrated that the proband's grandmother was the source of an X-linked SCID mutation. However, her T cells did not show the expected skewed $X$ chromosome inactivation pattern of female carriers of SCID, despite her having one affected son and two carrier daughters with skewed $\mathbf{X}$ inactivation. Single strand conformation polymorphism analysis of $I L 2 R G$ in the affected proband was abnormal in exon 5; sequencing revealed a nine nucleotide in-frame duplication insertion. The three duplicated amino acids included the first tryptophan of the "WSXWS" motif found in all members of the cytokine receptor gene superfamily. Mutation detection in the pedigree confirmed that the founder grandmother's somatic cells had only normal $I L 2 R G$, and further showed that the SCID-associated X chromosome haplotype was inherited by three daughters, one with a wild type IL2RG gene and two others with the insertional mutation. Female germ line mosaicism is unusual, but its presence in this X-linked SCID family emphasizes the limitations of genetic diagnosis by linkage as compared with direct mutation analysis. (J. Clin. Invest. 1995. 95:895-899.) Key words: cytokine receptor - WSXWS motif - genetic linkage $\cdot$ haplotype $\cdot$ single strand conformation polymorphism
\end{abstract}

\section{Introduction}

The most common form of human severe combined immunodeficiency (SCID) ${ }^{1}$ is caused by mutations in the X chromosome-

Address correspondence to Dr. J. M. Puck, NCHGR/NIH Bldg. 49, Rm.3W14, 49 Convent Drive, MSC 4470, Bethesda, MD 20892-4470. Phone: (301) 402-2194; FAX: (301) 402-4929.

Received for publication 2 August 1994 and in revised form 30 September 1994.

1. Abbreviations used in this paper: $\mathrm{AR}$, androgen receptor; $\mathrm{GM}$, grandmaternal; GP, grandpaternal; IL2RG, interleukin-2 receptor $\gamma$ chain gene; IL-2R $\gamma$, IL-2 receptor $\gamma$ chain protein; SSCP, single strand confirmation polymorphism; SCID, severe combined immunodeficiency.

The Journal of Clinical Investigation, Inc.

Volume 95, February 1995, 895-899 linked gene encoding the $\gamma$ chain of the interleukin-2 receptor complex $(I L 2 R G)(1,2)$. Estimated to occur in 1 in 10,000 to 100,000 births, X-linked SCID generally has a severe phenotype, with failure to thrive and infections leading to death before 18 mo of age unless successfully treated by bone marrow transplantation $(3,4)$. Patients have very few $\mathrm{T}$ cells and absent mitogen responses; although B cells are often present, immunoglobulin levels are low, and specific antibody production is lacking. Skewed $\mathrm{X}$ chromosome inactivation in lymphocytes is a hallmark of female carriers, reflecting a selective disadvantage during growth and maturation for lymphocyte progenitors bearing a SCID mutation on the active X chromosome (5).

Before the identification of $I L 2 R G$ as the X-linked SCID gene, indirect genetic methods were used for carrier testing and prenatal prediction (6). Linkage analysis using polymorphic DNA markers in SCID families had positioned the disease locus in the proximal long arm of the $\mathrm{X}$ chromosome, initially near the RFLP DXS159 (7), and more recently refined to Xq13.1, between DXS453 and DXS227 $(8,9)$.

Now that mutations causing SCID have been directly demonstrated in $I L 2 R G$, carrier testing and prenatal prediction can be performed with much greater certainty. A wide array of mutations in each of the eight exons of IL2RG has been seen (10). Moreover, newly occurring mutations can be traced to their origin, making possible accurate genetic prediction in cases where linkage analysis alone would be misleading. We report here a unique IL2RG mutation causing SCID in a multigeneration pedigree, in which the founder was a female germ line mosaic whose offspring inherited both mutant and wild type IL2RG genes on the same maternal chromosomal haplotype.

\section{Methods}

A large family of French Canadian descent included two male cousins diagnosed with SCID; one had died previously and the other died after the start of genetic evaluation. This patient was diagnosed at 6 mo of age and succumbed to complications following attempted treatment with T cell-depleted haploidentical bone marrow transplantation. A maternal uncle of the affected males was recognized in retrospect to have died of SCID at 9 mo of age following a history of failure to thrive, chronic diarrhea, and infections. A partial family pedigree is shown in Fig. 1 $A$. No information was available to ascertain whether additional relatives in or before generation I might have been affected with SCID. Blood samples for genetic analysis were obtained with informed consent from all living individuals shown except II-8; in addition, a pre-transplant blood sample was obtained with maternal consent from patient III-2, from which an EBV transformed B cell line was started. 
Table I. Sequence of Oligonucleotide Primers Flanking the Exons of IL2RG

\begin{tabular}{cclc}
\hline Exon & Position & \multicolumn{1}{c}{ Primer } & Product size \\
\hline & & & $b p$ \\
1 & $5^{\prime}$ & AAGCTATGACAGAGGAAACGTG & 292 \\
& $3^{\prime}$ & AGGCACCAGATCTCTGTACG & \\
2 & $5^{\prime}$ & CATTTCTCTTCCCTCCCTGC & 297 \\
& $3^{\prime}$ & GAGAAAACAGTGGGGTACCTGG & \\
3 & $5^{\prime}$ & TGCAGTACCCAGATTGGCC & 291 \\
& $3^{\prime}$ & TCCAATGTCCCACAGTATCCC & \\
4 & $5^{\prime}$ & GGTATTAGGGGCACTACCTTCAGG & 254 \\
& $3^{\prime}$ & GGCCTTAGCTGCTACATTCACG & \\
5 & $5^{\prime}$ & AGTAGCACAGATGACACTGGTGG & 312 \\
& $3^{\prime}$ & TAGAAAGGCTGGGGTGTTGG & \\
6 & $5^{\prime}$ & CAGTGCCTGGCATGTAGTAGG & 225 \\
& $3^{\prime}$ & ACCCTCCTCTGCTATTGTCAGC & \\
7 & $5^{\prime}$ & TTTGGTGATGGAAGGAAGCC & 271 \\
& $3^{\prime}$ & ACACTCTGTCTGTCTTGCTGGC & \\
8 & $5^{\prime}$ & TCCTGCCCCTAATTGACCC & 276 \\
& $3^{\prime}$ & CTTAGGGCTACAGGACCCTGG & \\
& & & \\
\hline
\end{tabular}

DNA and RNA were prepared by standard methods for Southern and Northern blots (11) and for PCR. Both RFLP and PCR-based microsatellite polymorphic $\mathrm{X}$-linked loci were used to define the genotype of family members as described (8). $\mathrm{X}$ chromosome inactivation analysis for females I-2, II-5, II-6, II-7, and III-3 was performed as described (12) by fusing polyclonal purified $T$ cells from each subject with hamster fibroblasts deficient in hypoxanthine phosphoribosyl transferase followed by metabolic selection for hybrid cells containing the active human $\mathrm{X}$ chromosome. A series of independent hybrids from each female was analyzed for DNA marker allele content by Southern blot to determine the frequency with which each $\mathrm{X}$ chromosome was active. $\mathrm{T}$ cell $\mathrm{X}$ inactivation in individual $\mathrm{I}-2$ was assessed by the additional method of analysis of methylation of the androgen receptor $(A R)$ polymorphic locus as described (13).

Single strand confirmation polymorphism (SSCP) analysis of each individual exon was carried out using DNA from all available family members. A hybrid cell line containing a single $\mathrm{X}$ chromosome, the active $\mathrm{X}$ from a $\mathrm{T}$ cell of individual II-7, was included in the analysis. Preamplification of $I L 2 R G$ from genomic DNA in three sections (exons $1-3,4-5$, and 6-8) was initiated with a $30 \mathrm{~m}$ heat soak at $94^{\circ} \mathrm{C}$ and was performed in a thermal cycler (model 9600; Perkin Elmer-ABI, Foster City, CA). Primer sequences, shown in Table I, were derived from the published genomic sequence, GenBank accession no. L19546 (2). Subsequent amplifications for SSCP analysis used primers flanking each exon (Table I) end labeled with $\gamma^{32}$ P-ATP (Redivue; Amersham Corp., Arlington Heights, IL). Exon 5 primers amplified a 312-bp fragment including the 163-bp exon. PCR reactions contained 10-100 ng of genomic DNA or $1 \mathrm{ng}$ of preamplified DNA in a volume of 10-50 $\mu \mathrm{l}$, $1.25 \mathrm{U}$ AmpliTaq polymerase (Perkin Elmer-ABI), and the following reagent concentrations: each primer, $0.5 \mu \mathrm{M}$; each dNTP, $200 \mu \mathrm{M} ; 50$ $\mathrm{mM} \mathrm{KCl}, 10 \mathrm{mM}$ Tris $\mathrm{HCl}, \mathrm{pH} 8.3,1.5 \mathrm{mM} \mathrm{MgCl}_{2}$ and $0.001 \%$ (wt/ vol) gelatin. Cycling conditions were $94^{\circ} \mathrm{C}$ for $5 \mathrm{~m}$ followed by 25 cycles of $94^{\circ} \mathrm{C}$ for $45 \mathrm{~s}, 61^{\circ} \mathrm{C}$ for $60 \mathrm{~s}$, and $72^{\circ} \mathrm{C}$ for $120 \mathrm{~s}$. Products were diluted in formamide loading buffer (14), denatured by boiling, immediately cooled on ice, and electrophoresed at $7 \mathrm{~W}$ for $15 \mathrm{~h}$ at room temperature through $0.4 \mathrm{~mm}$ thickness $38 \times 30 \mathrm{~cm}$ modified acrylamide gels (Hydrolink MDE; AT Biochem, Malvern, PA). Gels were dried and exposed to $\mathrm{X}$-ray film.

Direct sequencing of PCR products from exon 5 was carried out using a Cyclist sequencing kit (Stratagene, La Jolla, CA) on multiple independently amplified samples from all available family members Either exon 5 primer was end labeled with ${ }^{32} \mathrm{P}$. Sequence was compared to the published consensus sequence (2).

\section{Results}

Genotyping. Linked markers were used to establish haplotypes for the family in the proximal long arm of the $\mathrm{X}$ chromosome (Fig. $1 A$ ). No family member had a crossover in the SCID/ IL2RG region bounded by DXS159 in Xq12 and PGK1 in $\mathrm{Xq13.3}$. The closest informative flanking markers for this family were the RFLP DXS159 itself, $10.7 \mathrm{cM}$ proximal to the SCID disease locus, and the microsatellite polymorphic marker locus DXS441, < $0.1 \mathrm{cM}$ distal (8). The grandpaternal (GP) haplotype of individual I-1 (Fig. $1 \mathrm{~A}$ ) was inferred from his four daughters as $\{\mathrm{DXS} 159-5.5 \mathrm{~kb}$, DXS441-185bp \}, illustrated by a black bar in Fig. $1 \mathrm{~A}$; the two $\mathrm{X}$ chromosomes of his wife, $\mathrm{I}-2$, had grandmaternal haplotypes \{ DXS159-1.6kb, DXS441$177 b p\}$ (white bar, GM1), and \{DXS159-5.5kb, DXS441$175 b p$ \} (gray bar, GM2). The GM2 haplotype was inherited by the two living males, II- 3 and II-4, who both have completely normal immunity, and also by II-5, a woman who has had two immunocompetent sons. Conversely, the GM1 haplotype was passed to II-6 and II-7, both of whom had sons affected with SCID. This same GM1 haplotype was found in the pretransplant blood sample from affected male III-2, the only affected patient alive at the beginning of the study. The inheritance of SCID in this family could therefore most easily be explained by an IL2RG mutation on the $\mathrm{X}$ chromosome with the GM1 haplotype of individual I-2; this mutation would have caused SCID in males II-1, III-1, and III-2, and made females II-6, II-7, and III-3 carriers of X-linked SCID.

Individual II-2 also inherited her mother's GM1 haplotype; she is the mother of one unaffected son (not shown); nonetheless, by linked markers she was predicted to be a carrier of $\mathrm{X}$ linked SCID.

$X$ inactivation analysis. Multiple human T cell/hamster hybrid cell lines were generated from females in the pedigree and grown in selective conditions to isolate the active human $X$ chromosome for determination of $\mathrm{X}$ inactivation patterns. Insufficient blood was available to isolate $T$ cells for $X$ inactivation analysis in female II-2. Females II-6, II-7, and III-3 had only their paternal $X$ chromosome as the active $X$ in at least 17 independent hybrids. Such skewed $\mathrm{X}$ chromosome inactivation in T lymphocytes (designated $S$ in Fig. $1 A$ ) is diagnostic of female carriers of the X-linked form of SCID, with a carrier/ non-carrier likelihood ratio of $>1,000: 1$ (12). As expected, female II-5, with the GM2 maternal haplotype, had random X inactivation ( $R$ in Fig. $1 A) ; 13$ hybrids had a maternal and 13 a paternal active $\mathrm{X}$ chromosome.

Contrary to expectation, female I-2 was found to have random $\mathrm{X}$ chromosome inactivation in the hybrids made from her T cells. 11 of 13 independent hybrids (carrier/non-carrier likelihood ratio $<0.0001$ ) contained an active $\mathrm{X}$ with the GM1 haplotype \{DXS159-1.6kb, DXS441-177\}, which in subsequent generations was associated with the SCID phenotype. The non-carrier pattern of random $X$ inactivation in the $T$ cells of I- 2 was confirmed by demonstrating equal methylation of her two alleles at the differentially methylated $A R(\mathrm{CAG}) \mathrm{n}$ polymorphic locus (13) (data not shown). The discrepancy between the somatic phenotype of female I-2, manifested by random $\mathrm{T}$ cell $\mathrm{X}$ inactivation, and her germ line transmission of $\mathrm{X}$-linked 
A

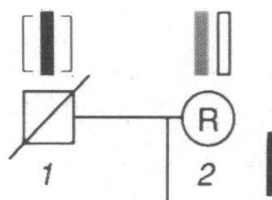

II

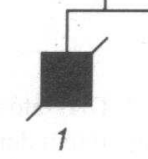

III

B

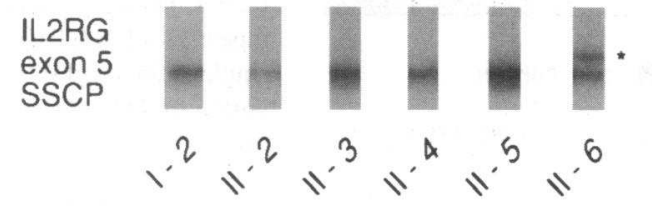

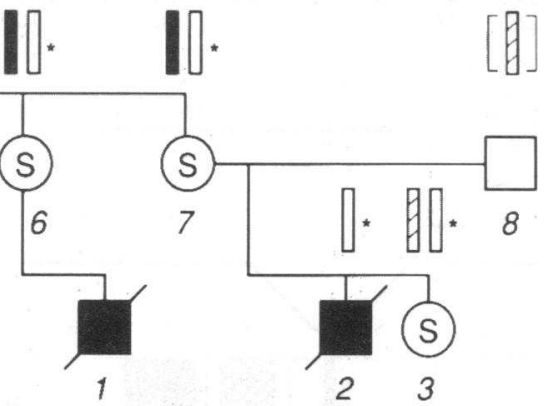

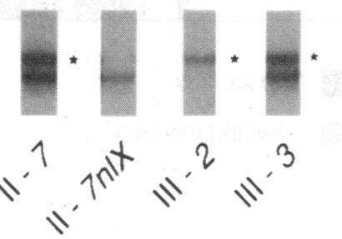

Figure 1. (A) Partial pedigree of a large French Canadian family with SCID. Pedigree symbols are as follows: Squares, males; circles, females; filled symbols, individuals affected with SCID; diagonal slashes, decreased. Bars above the pedigree symbols denote the individuals' $X$ chromosomal haplotypes as defined by polymorphic loci in the Xq12-q13 region (see text). For the two males not studied directly, an inferred haplotype is enclosed by square brackets. $\mathrm{X}$ chromosome inactivation patterns in $T$ lymphocytes of females, where tested, are depicted as random $(R)$ or skewed $(S)$. (B) SSCP patterns of exon 5 of $I L 2 R G$ in individuals in the pedigree, each shown under its corresponding pedigree symbol. (Asterisk) Mutant IL2RG allele.
SCID to multiple offspring who inherited the GM1 haplotype raised the possibility of a new germ line mutation in I-2.

Screening for IL2RG mutations. Evidence for mutation of $I L 2 R G$ in the family was first sought by Northern and Southern blot analysis. Total RNA from the B cell line established before bone marrow transplantation of the affected male III- 2 showed normal quantity and size of $I L 2 R G$ mRNA. This patient's genomic DNA on Southern blots with several restriction enzymes was similarly indistinguishable from normal. These negative findings indicated that the mutation in this family, like others described to date for $I L 2 R G$ in SCID patients, would be a small change at the nucleotide sequence level.

Therefore, SSCP analysis was undertaken for all eight $I L 2 R G$ exons amplified from genomic DNA of patient III-2. Normal migration patterns were seen in all of his $I L 2 R G$ exons except exon 5, which migrated more slowly than normal, strongly suggesting an exon 5 IL2RG mutation as the cause of SCID in this family. DNA from all available family members was subjected to exon 5 SSCP detection (Fig. $1 B$ ). The retarded signal from patient III-2, seen as an upwardly shifted band marked with an asterisk in Fig. $1 \mathrm{~B}$, was also seen in combination with the normally migrating band in females II-6, II-7, and III-3, consistent with their diagnosis as heterozygous carriers of $\mathrm{X}$-linked SCID. As shown, only the normal band was detected in a hybrid from II-7 containing the active, GP X chromosome from her T cells. DNA from individuals II-3, II-4, and II-5, who inherited only non-SCID-associated haplotypes, had only normal SSCP migration as expected.

As predicted by the random $\mathrm{T}$ cell inactivation analysis in female I-2, DNA from three different hematopoetic cell lineages, including B cells (shown), T cells, and granulocytes, had no trace of the upper, mutant $I L 2 R G$ exon 5 band. Moreover, her daughter, II-2, likewise had only the normal SSCP band, indicating that she had inherited a non-mutant IL2RG gene on the same GM1 haplotype as the mutant $I L 2 R G$ alleles inherited by her two carrier sisters.

Sequence analysis. Exon 5 of $I L 2 R G$ was sequenced directly using PCR products from genomic DNA of the affected boy
III-2 and his relatives. A 9-bp duplication insertion of cDNA nucleotides 717-725 was found, predicted to result in the duplication of amino acids 235-237 (Fig. 2). The three female carriers, II-6, II-7, and III-3 had both duplicated and normal $I L 2 R G$ sequence, while all other living family members, including I-2 and II-2, had only normal sequence.

\section{Discussion}

Identification of the gene which is defective in X-linked SCID has made possible the direct detection of mutations in individuals at risk. While indirect approaches have been useful for prenatal prediction and carrier testing for many SCID families, in other families suitable pedigree structure or samples to establish $\mathrm{X}$-linked inheritance may be lacking. Furthermore, the possibility of germ line mosaicism cannot be addressed by linkage analysis.

In the family reported here, a mutation in $I L 2 R G$ was traced to a female founder whose somatic cells showed no mutation at the level of resolution of PCR in our SSCP analysis. The lack of mutation in her $\mathrm{T}$ cells was in accord with her random $\mathrm{X}$ chromosome inactivation. DNA from B cells and granulocytes were also non-mutant, but other non-hematopoetic tissues were not available for testing; thus some degree of somatic mosaicism cannot be ruled out. However, her descendants' genotypes clearly indicate that she had both mutant and wild type cells in her oocyte progenitors. Direct detection of the mutation by SSCP and by targeted DNA sequencing of the abnormal exon proved that the founder I-2 had passed both wild type and mutant $I L 2 R G$ genes to her offspring on the same X chromosomal haplotype.

Indirect carrier prediction based on linked marker alleles and haplotype analysis has been a pillar of genetic management, recognizing the limitation that an incorrect result may be obtained in a situation where new mutations or germ line mosaicism are present. In the family in this report, individual II-2 was initially predicted to have a high likelihood of being a carrier based on linkage alone; however, direct mutation analy- 


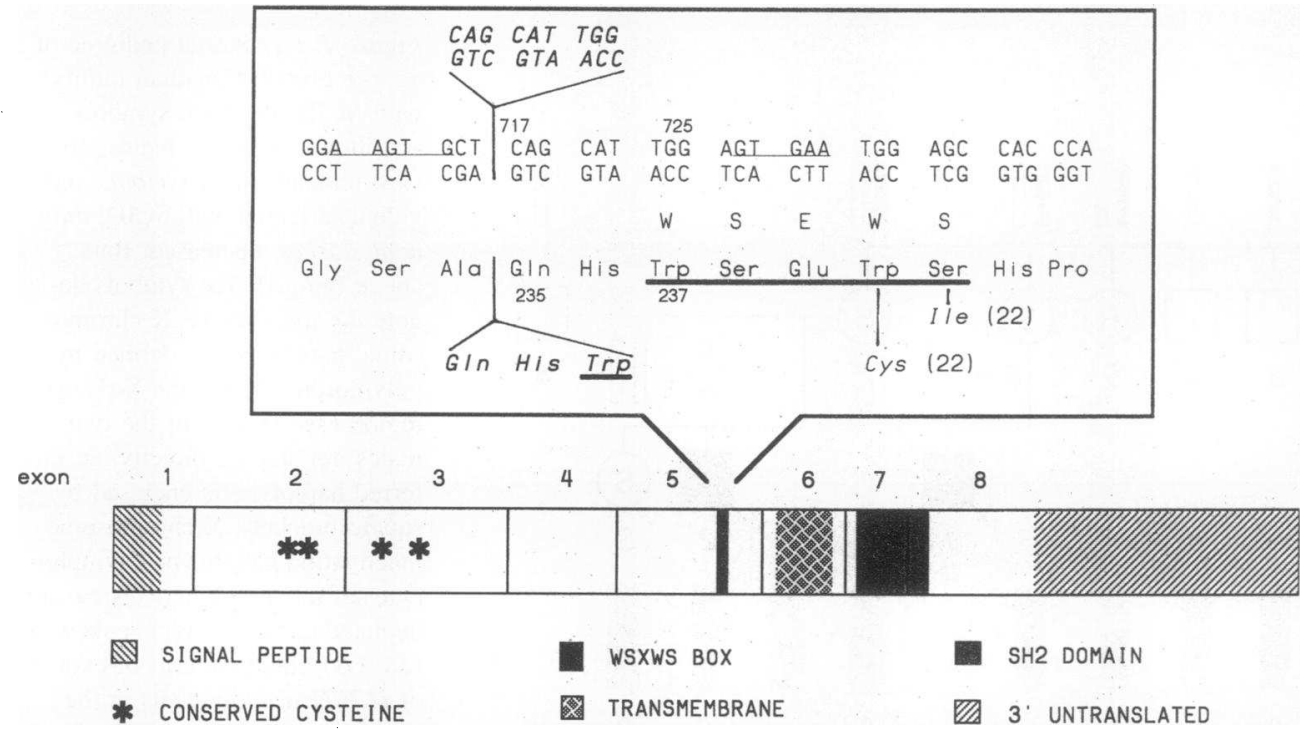

Figure 2. Diagram of IL2RG showing protein domains encoded by each of the eight exons $(1,2)$ The enlarged area indicates the site of SCID mutations involving the WSXWS motif including the 9-bp duplication insertion in our family flanked by inverted 5-bp repeats at cDNA 710-731. The single amino acid substitutions reported by DiSanto et al. (22) are also indicated. sis once the gene defect was defined at the molecular level reduced her carrier risk to virtually nil. Ours is the first report of female germline mosaicism without somatic evidence of mutation in X-linked SCID. However, germline mosaicism with or without somatic mosaicism has been documented in over a dozen different genetic disorders (reviewed in reference 15), including the $\mathrm{X}$-linked recessive diseases Duchenne muscular dystrophy $(16,17)$, hemophilia $A(18)$ and $B(19)$, and Xlinked agammaglobulinemia (20). The frequenčy is unknown and may vary greatly depending on the gene and type of mutation. For example, in Duchenne muscular dystrophy, for which most mutations are large deletions, the recurrence risk for sisters or mothers of a sporadic male is emperically estimated at $14 \%$ for future male pregnancies with the same X haplotype (17), but there are no comparable estimates available for the type of small mutations in IL2RG which cause SCID.

Fig. 2 shows the protein domains of the IL $2 \hat{R} G$ gene, including the four cysteine residues with conserved spacing, the "WSXWS" motif in exon 5 and the transmembrane region, all of which define $I L 2 R G$ as a member of the cytokine receptor supergene family. SSCP analysis of genomic DNA from our SCID patient and carrier family members followed by direct sequencing of $\mathrm{PCR}$ products revealed a nine nucleotide in-frame duplication insertion in $I L 2 R G$ exon 5. The mechanism for this mutation is likely to have involved gap repair following replication-associated mispairing of the five nucleotide inverted repeat sequence "AAGTG. . .GTGAA", which surrounds the duplicated bases (see cDNA 710-731, Fig. 2) (21). The resulting predicted protein sequence has a duplication of three extracellular amino acids (glutamine, histidine, and tryptophan) just adjacent to and including the first tryptophan of the WSXWS motif. Preliminary results of flow cytometric analysis with an antibody to the IL-2 receptor $\gamma$ chain (IL-2R $\gamma$ ) show detectable protein on the surface of EBV-transformed B cells from the patient (Puck, J. M., manuscript in preparation); thus production and expression of an abnormal IL-2R $\gamma$ protein appears to occur as a result of this mutation.

Although the precise nature of the immunologic lesion produced by the duplication of these three amino acids in IL-2R $\gamma$ has not been determined, two other SCID-affected patients have been reported with point mutations causing amino acid substitutions in the second tryptophan and serine of the WSXWS sequence (22) as shown in Fig. 2. Furthermore, several observations on naturally occurring (23) and experimental mutation of the WSXWS region in receptors related to $\mathrm{IL}-2 \mathrm{R} \gamma$, including the $\beta$ chain of $I L-2$ receptor (24) and receptors for growth hormone (23), erythropoietin (25), and granulocyte-macrophage colony stimulating factor (26), indicate that changes in and adjacent to this motif invariably disrupt receptor function.

IL- $2 R \gamma$. is found in multiple cytokine receptor complexes, including IL-2, IL-4, and IL-7 receptors (27-29). While IL-2 is the major $\mathrm{T}$ cell stimulatory cytokine, $\mathrm{IL}-4$ induces $\mathrm{B}$ cell class switching, and IL-7 is a growth factor for both thymocytes and pre-B cells. Although neither the precise role of IL- $2 \mathrm{R} \gamma$ in cytokine responses nor the disruptive effect of specific mutations such as the one in this family are yet understood, the wealth of distinct IL2RG mutations in X-linked SCID patients such as ours will facilitate dissection of the relative contribution of each cytokine in producing the SCID phenotype.

\section{Acknowledgments}

The authors appreciate assistance from and stimulating discussions with Fredric Rosenberg, Judith Isakov, Robert Nussbaum, and Trudie Small.

\section{References}

1. Noguchi, M., Y. Huafang, H. M. Rosenblatt, A. H. Filipovitch, S. Adelstein, W. S. Modi, O. W. McBride, and W. J. Leonard. 1993. Interleukin-2 receptor $\gamma$ chain mutation results in $\mathrm{X}$-linked severe combined immunodeficiency in humans. Cell. 73:147-157.

2. Puck, J. M., S. M. Deschenes, J. C. Porter, A. S. Dutra, C. J. Brown, H. F. Willard, and P. S. Henthorn. 1993. The interleukin-2 receptor $\gamma$ chain maps to Xq13.1 and is mutated in X-linked severe combined immunodeficiency, SCIDX1. Hum. Mol. Genet. 2:1099-1104.

3. WHO Scientific Group on Immunodeficiency. 1992. Primary immunodeficiency diseases. Immunodefic. Rev. 3:195-236.

4. Puck, J. M. 1993. X-linked immunodeficiencies. In Advances in Human Genetics. H. Harris and K. Hirschhorn, editors. Plenum Press, New York. $107-$ 144.

5. Puck, J. M., R. L. Nussbaum, and M. E. Conley. 1987. Carrier detection in $\mathrm{X}$-linked severe combined immunodeficiency based on patterns of $\mathrm{X}$ chromosome inactivation. J. Clin. Invest. 79:1395-1400. 
6. Puck, J. M., C. M. Krauss, S. M. Puck, R. H. Buckley, and M. E. Conley. 1990. Prenatal test for X-linked severe combined immunodeficiency by analysis of maternal X-chromosome inactivation and linkage analysis. N. Eng. J. Med. 322:1063-1066.

7. de Sainte Basile, G., B. Arveiler, I. Oberlé, S. Malcolm, R. Levinsky, Y. Lau, M. Ho f ker, M. Debre, A. Fischer, C. Griscelli, and J.-L. Mandel. 1987. Close linkage of the locus for $\mathrm{X}$ chromosome-linked severe combined immunodeficiency to polymorphic DNA markers in Xq11-13. Proc. Natl. Acad. Sci. USA. 84:7576-7579.

8. Puck, J. M., M. E. Conley, and L. C. Bailey. 1993. Refinement of linkage of human severe combined immunodeficiency (SCIDX1) to polymorphic markers in Xq13. Am. J. Hum. Genet. 53:176-184.

9. Markiewicz, S., J. P. DiSanto, J. Chelly, N. Fairweather, B. Le Marec, C. Griscelli, M. B. Graeber, U. Muller, A. Fischer, A. P. Monaco, and G. de Sainte Basile. 1993. Fine mapping of the human SCIDX1 locus at Xq12-13.1. Hum. Mol. Genet. 2:651-654.

10. Puck, J. M. 1994. Molecular basis for three X-linked immune disorders. Hum. Mol. Genet. 3(Review): 1457-1461.

11. Sambrook, J., E. Fritsch, and T. Maniatis. 1989. Molecular Cloning: A Laboratory Manual. Cold Spring Harbor Press, Cold Spring Harbor, NY.

12. Puck, J. M., C. C. Stewart, and R. L. Nussbaum. 1992. Maximum likelihood analysis of human $\mathrm{T}$-cell $\mathrm{X}$ chromosome inactivation patterns: normal women versus carriers of X-linked severe combined immunodeficiency. Am. J. Hum. Genet. 50:742-748.

13. Allen R. C., H. Y. Zoghbi, A. B. Moseley, H. M. Rosenblatt, and J. W. Belmont. 1992. Methylation of HpaII and HhaI sites near the polymorphic CAG repeat in the human androgen-receptor gene correlates with $\mathrm{X}$ chromosome inactivation. Am. J. Hum. Genet. 51:1229-1239.

14. Orita, M., H. Iwahana, H. Kanazawa, K. Hayashi, and T. Sekiya. 1989. Detection of polymorphisms of human DNA by gel electrophoresis as singlestrand conformation polymorphisms. Proc. Natl. Acad. Sci. USA. 86:2766-2770.

15. Hall, J. G. 1988. Review and Hypotheses: Somatic mosaicism: observations related to clinical genetics. Am. J. Hum. Genet. 43:355-363.

16. Darras, B. T., P. Blattner, J. F. Harper, A. J. Spiro, S. Alter, and U. Francke. 1988. Intragenic deletions in 21 Duchenne muscular dystrophy (DMD)/ Becker muscular dystrophy (BMD) families studied with the dystrophin cDNA: location of breakpoints on HindIII and BglII exon-containing fragment maps, meiotic and mitotic origin of the mutations. Am. J. Hum. Genet. 43:620-629.

17. Bakker E., H. Veenema, J. T. Den Dunnen, C. van Broeckhoven, P. M Grootscholten, E. J. Bonten, G. J. B. van Ommen, and P. L. Pearson. 1989.
Germinal mosaicism increases the recurrence risk for "new" Duchenne muscular dystrophy mutations. J. Med. Genet. 26:553-559.

18. Bröcker-Vriends, A. H. J. T., E. Briët, J. C. F. M. Dreesen, B. Bakker, P. Reitsma, Pannekoek, J. J. P. van de Kamp, and P. L. Pearson. 1990. Somatic origin of inherited haemophilia A. Hum. Genet. 85:288-292.

19. Gitschier, J. 1988. Maternal duplication associated with gene deletion in sporadic hamophilia. Am. J. Hum. Genet. 43:274-279.

20. Hendriks, R. W., E. J. B. M. Mensink, M. E. M. Kraakman, A. Thompsom, and R. K. B. Schuurman. 1989. Evidence for male X chromosomal mosaicism in X-linked agammaglobulinemia. Hum. Genet. 83:267-270.

21. Cooper, D. N., and M. Krawczak. 1993. Human Gene Mutation. Bios Scientific Publishers, Oxford, UK. 209-217.

22. DiSanto, J. P., A. Dautry-Varsat, S. Certain, A. Fischer, and G. de Saint Basile. 1994. Interleukin-2 (IL-2) receptor $\gamma$ chain mutations in X-linked severe combined immunodeficiency disease result in the loss of high-affinity IL-2 receptor binding. Eur. J. Immunol. 24:475-479.

23. Duriez, B., M. L. Sobrier, P. Duquesnoy, M. Tixier-Bouchard, E. Decuypere, G. Coquerelle, M. Zeman, M. Goossens, and S. Amselem. 1993. A naturally occurring growth hormone receptor mutation: in vivo and in vitro evidence for the functional importance of the WS motif common to all members of the cytokine receptor superfamily. Mol. Endocrinol. 7:806-814.

24. Miyazaki, T., M. Maruyama, G. Yamada, M. Hatakeyama, and T. Taniguchi. 1991. The integrity of the conserved "WS motif" common to IL-2 and other cytokine receptors is essential for ligand binding and signal transduction. EMBO (Eur. Mol. Biol. Organ.) J. 11:3191-3197.

25. Ihle, J. N., F. W. Quelle, and O. Miura. 1993. Signal transductuction through the receptor for erythropoietin. Semin. Immunol. 5:375-389.

26. Nakagawa, Y., K. Hiroshi, A. Miyajima, K. Arai, and T. Yokota. 1994. Structure of the gene encoding the $\alpha$ subunit of the human granulocyte-macrophage colony stimulating factor receptor. J. Biol. Chem. 269:10905-10912.

27. Russel, S. M., A. D. Keegan, N. Harada, Y. Nakamura, M. Noguchi, P. Leland, M. C. Friedmann, A. Miyajima, R. K. Puri, W. E. Paul, and W. J. Leonard. 1993. Interleukin-2 receptor $\gamma$ chain: a functional component of the interleukin4 receptor. Science (Wash. DC). 262:1880-1883.

28. Noguchi, M., Y. Nakamura, S. M. Russell, S. F. Ziegler, M. Tsang, X. Cao, and W. J. Leonard. 1993. Interleukin-2 receptor $\gamma$ chain: a functional component of the interleukin-7 receptor. Science (Wash. DC). 262:1877-1880.

29. Kondo, M., T. Takeshita, N. Ishii, M. Nakamura, S. Watanabe, K. Arai, and K. Sugamura. 1993. Sharing of the interleukin-2 (IL-2) receptor $\gamma$ chain between receptors for IL-2 and IL-4. Science (Wash. DC). 262:1874-1877. 